\title{
Hanna Diamond, Fleeing Hitler: France 1940 (Oxford: Oxford University Press, 2007).
}

\section{Marla Epp, University of Alberta}

On May 10, 1940, the Nazis attacked France, ending the period of military inactivity known as the "Phony War." French citizens in the regions under attack hastily assembled a few possessions, took to the roads, and fled towards the River Loire and the south. By June 14, 1940, when the Nazis entered Paris, over two million Parisians had fled the city, joining the crowds of refugees from North-east France, Belgium, and the Netherlands. The roads were filled with people, mostly women, children, and the elderly, as well as cars, trucks, bicycles, wheelbarrows, carts, strollers - everything, even the people, loaded down with whatever few possessions they had been able to bring with them. Many evacuees had no food, other provisions, or shelter, and they were at risk of being attacked and robbed. They were also exposed to the more serious threat of German air raids, which grew more frequent and intense as more and more French soldiers joined the crowds on the roads. The images of the exodus, as the mass movement became known, are familiar from photographs and newsreels of the time as well as written descriptions, and are often used as an opening for both historical and fictional works dealing with World War II and France. However, in spite of the magnitude of the mass movement, the exodus is usually seen as a preface to the Nazi military occupation of France rather than as an event worthy of consideration in its own right.

\author{
Past Imperfect \\ 16 (2010) | @ | ISSN 1711-053X | eISSN 1718-4487
}


Fleeing Hitler: France 1940, the first book written in English to focus exclusively on the exodus, proves the error of this assumption and shows that the exodus was an important and complex event that both merits and rewards extensive study. Although the period of the exodus did not last beyond the autumn of 1940, it played an important role in influencing people to accept Marshall Pétain's government and the armistice signed between France and Germany on June 22, 1940 and in setting up the early dynamics of the occupation. In this book, Hanna Diamond, a senior lecturer in French History at the University of Bath, not only raises important historical points but also interesting questions pertaining to the collective memory of the exodus.

Fleeing Hitler is scholarly yet accessible, written without pretension or excessive jargon, and is targeted to interest both academics and general readers. Much of this interest is due to the excellent quality of Diamond's research. Because there are few secondary sources even in French that deal specifically with this topic, she draws on official documents and testimonials. These eyewitness accounts include diaries, memoirs, and personal interviews, many of which were conducted specifically for this book. Diamond uses accounts from a wide variety of people of different social classes and of both genders. For example, a citation from Simone de Beauvoir is given the same value as an excerpt from an interview with an unknown woman from the lower-middle class or a quotation from the diary of Georgette Guillot, a secretary at the Ministry of the Interior. Diamond makes full use of lengthy excerpts from these first-hand accounts, in which people who experienced the exodus talk 
about their personal observations, emotions, and reactions, to create a nuanced and compelling description of the era.

Such a description is her goal, as she states clearly in the preface: "My intention has been to write an accessible detailed account of the experiences of civilians and soldiers caught up in the events of spring-summer 1940 in France" (p. vii). Over the course of the book, she succeeds in creating a vivid picture of the exodus that emphasizes the complexities and uncertainties of the era. Diamond's use of personal accounts and, to a lesser extent, photographs, individualizes the flood of refugees and reinforces the variety of their experiences. She removes the sense of homogeneity sometimes associated with the mass of civilians participating in the exodus and discusses the different groups of people who had taken to the road: young and old, men and women, children, Jews, civilians, soldiers, rich people, peasants, and others.

The main strength of this book lies in its creation of a vivid and detailed portrait of the exodus; however, Diamond also raises pertinent analytical points. Her discussion of the interactions between governmental decisions and public opinion is particularly interesting. Before the Nazi attack, Paul Reynaud's government had prevaricated over setting up plans for an eventual evacuation, citing as a reason the concern of keeping up the public's morale, and had continued to focus public opinion on the likelihood of a French victory. The public was unprepared for the evacuation and the defeat and harboured resentment against the government. Diamond shows how Marshall Pétain used this resentment, as well as the people's fear and confusion, to his advantage in gaining support for his government and the armistice. "Rather than dwelling on the routed and defeated 
army, he focused instead on the plight of the refugees, women, children, and the elderly, implying that his approach to the enemy was predominantly motivated by a desire to bring their suffering to an end" (p. 102). The Vichy government further manipulated the population through a savvy propaganda campaign, and Diamond shows how people's experiences of the exodus made them particularly susceptible to the propaganda for Pétain's "National Revolution," the slogan of which was Travail, famille, patrie (Work, Family, Fatherland). Refugees from the cities had relied on the hospitality of peasants and were therefore reminded of the importance of rural France. Propaganda emphasized the people's rural roots and pushed for a return to traditional social norms as a means of regaining the stability shattered by the exodus.

Diamond's analysis of the second part of the exodus, the "repatriation" or return home, or, alternatively, the final attempt to reach the non-occupied zone or to cross the border before it was closed, is also illuminating. Diamond shows how this period, although rarely discussed in detail in other historical books, was key in establishing the initial interactions between Nazi soldiers and French civilians. Fearful of inciting a mass resistance movement, the German soldiers were under strict orders to act with courtesy towards the French. "The Germans were frequently helpful to lost and stranded refugees, picking them up on convoys and distributing petrol where they could. Their amiability was no accident" (p. 145). Thanks to the German soldiers' organizational talents, the return home was much smoother than the initial exodus, gaining the soldiers the gratitude of many refugees. 
The exodus was a time of panic and uncertainty, and civilians did not know what was going to happen, who would win the war, or even if they would survive they day. Getting reliable news was difficult, and people's uncertainty increased as French soldiers began to join the crowds. Even in the days surrounding the armistice, both civilians and soldiers were confused: "Should they continue fighting until they had formal orders to the contrary? Or should they give themselves up to the enemy? Should they participate in an orderly withdrawal? Or should they endeavour to escape on an individual basis and make for the safety in the south?" (p. 114). One of the most engaging aspects of Diamond's discussion is her willingness to describe and focus on the confusion and complexity of the period rather than imposing a linear analysis unsupported by the evidence.

Unfortunately, this same positive quality, the desire to maintain and show the complexity of the era, combined with Diamond's goal of providing an overview that deals with as many aspects of the exodus as possible, also leads to one of the weaknesses of the book, its lack of direction. Diamond touches on a lot of material in a relatively slim volume - approximately 250 pages - but she often omits explanations, clarifications, and links between ideas or paragraphs that would have made the book easier to follow. The progression of the discussion mirrors the routes of the people on the road during the exodus: there is much to see, to absorb, and to observe, but the path is uncertain. Diamond does not hesitate to take a small detour to explore something only vaguely related to the argument at hand, and, while these points are often interesting, they break the flow of the discussion. 
Headings help indicate the direction of the discussion, but ideas unrelated to the heading often find their way into the section. In one particularly jarring case, after analyzing the return home of civilians after the exodus, Diamond jumps without warning to General de Gaulle's return to Paris in 1944, failing to integrate it into the overall arc of the book. While a historically significant point that would have been understandable in the book's conclusion, this discussion sits awkwardly at the end of one of the middle chapters. Diamond herself seems to be aware of the strange placement of this aside, and writes: "Let us now return to consider the situation of those who returned to their homes in the autumn 1940" (p. 169), the very point she was discussing before abruptly shifting her attention to de Gaulle's return. Even when the points being discussed in a section are all loosely related, Diamond often fails to indicate clearly the relationship between a personal anecdote and the historical analysis immediately following or preceding it. For example, Diamond moves from an anecdote about a family's opinions on Pétain to a general statement relating to how the fear and disorder of the period made people more likely to accept the occupying forces. While the two statements are related, an initial sentence to bridge the gap would have strengthened the argument. In addition, many of the key analytical moments are buried in the middle of a section, easily ignored between two lengthy citations. It would perhaps have been helpful to have concluding sentences at the end of each chapter to reinforce the main points of the discussion.

Fleeing Hitler also suffers at times from an uneasy balance between wanting to give a description of many points and an analysis of a few. Diamond raises many interesting points,

\section{Past Imperfect}

16 (2010) | @ | ISSN 1711-053X | elSSN 1718-4487 
but her ideas are not always fully expanded and analytical arguments are touched upon but not developed. For example, although she mentions the experiences of Jews during this period, her analysis is sparse and does not properly consider the lasting effects of the exodus on the situation of Jews in France. Diamond has only one chapter that deals with a topic in depth, that concerning the end of the Third Republic and the formation of the Vichy government. While a relevant discussion, her focus on the secret discussions and negotiations that led to the political event seems out of keeping with the rest of the book, whose focus is on the individual soldiers and civilians and their reactions to the decrees and the situation.

The personal accounts are an important part of what makes this book enjoyable to read, but they could have occasionally been better framed. Diamond sometimes omits to introduce the person being quoted, leaving their social sphere and even whether they were an eyewitness or a historian unclear. Although this information is available either in the footnotes or in the "Further Reading," it would have been helpful if it were repeated in the body of the text. Explaining whether the statements of individuals could be applied more broadly or whether they represent an exception would also have made some of the arguments stronger. Diamond does not discuss whether an account was written at the time of the exodus or later, with the benefit of hindsight, and whether this would make any difference to the interpretation of the description. She also waits until the conclusion to caution the reader that some of the statements may be strongly influenced by personal beliefs or ideologies, but does not draw attention to writers' biases during the main part of the book. 
Although Diamond generally avoids making
generalizations or unsubstantiated or strongly subjective comments, there are a few judgemental remarks, especially in the conclusion of the book, that force the reader to question her objectivity. Diamond's remarks about Irène Némirovsky seem to be particularly unfounded. Ironically, although she omits to tell the reader about the ideology of the eyewitnesses being quoted, she explicitly draws attention to the lack of ideology in Némirovsky's fictional account of the exodus in Suite française, a novel written during the occupation. Diamond declares: "This decision to adopt such a neutral position is a serious shortcoming, but does not diminish the moving evocation of 1940 that this work achieves" (p. 237). Némirovsky herself consciously chose to avoid writing an overtly didactic book, aiming rather at writing a work of fiction that would move people regardless of their politics or their time period: "Never forget that the war will be over and the entire historical side will fade away. Try to create as much as possible: things, debates...that will interest people in 1952 or 2052."1

Fleeing Hitler is a rich, fully detailed monograph. The problems stem from a wealth of information and a desire to follow too many threads, rather than from faulty research or analysis. Although there are organizational difficulties and occasional losses of focus, the overall discussion remains compelling. The first-hand accounts add human interest and pertinent details to historians' understanding of the exodus, and Diamond draws attention to the various facets and complexities of the period,

\footnotetext{
${ }^{1}$ Irène Némirovsky, Suite française (Toronto: Vintage Canada, 2007), 383.

Past Imperfect

16 (2010) | @ | ISSN 1711-053X | elSSN 1718-4487
} 
showing at the same time that there is still much more to be researched and said about the exodus. In spite of the moments of confusion, Fleeing Hitler achieves what Diamond states in the introduction that she set out to do: "This book will argue that the exodus was a pivotal moment for the people of France. It will show how the trauma of the exodus left the French vulnerable and confused" (p. 12). The various sources, facts, and aspects of the exodus coalesce to create a description of a complicated era of trauma, uncertainty, and fear. 